\title{
CRYPTIC SLEEPING POSTURE OF A SKIPPER BUTTERFLY, ERYNNIS BRIZO*
}

\author{
By John M. Burns \\ Museum of Comparative Zoology, Harvard University
}

Hesperiids have seldom been observed asleep in nature. A major exception to this general statement is provided by the hesperiine Thymelicus lineola (Ochsenheimer), an early twentieth century accidental import from Eurasia now thriving in much of its expanding North American range (Arthur 1966; Burns 1966). The extraordinarily high density attained by colonizing populations of $T$. lineola has drawn attention even to dormant individuals. Hensel ( 1966) found numerous examples clinging to vegetation in early evening at Edmundston, New Brunswick, and easily sampled them by hand. I similarly sampled $T$. lineola on the evening of 24 June 1968 in a pasture at Durham, Middlesex County, Connecticut, where it abounded, although it had begun to appear in that region only five years before (Apter and Burns 1965). The sleeping skippers sat exposed on leaves, stems, and flowers of forbs and grasses, with the upper sides of the wings together above the back a position commonly assumed by these skippers when momentarily at rest in the course of diurnal activity. There was no suggestion of concealing behavior.

In contrast to this are two observations on a native pyrgine, Erynnis brizo (Boisduval and Leconte), made when I was collecting genitalic differentiates of this species, and natural hybrids between them, in Texas (Burns and Gillmor, in preparation). E. brizo characteristically rests between diurnal flights with both pairs of wings stretched out horizontally.

In pine and scrubby oak habitat along park road $P_{I}$ between Bastrop and Buescher state parks, Bastrop County, Texas, on I4 March 1967, at 1730 hours C.S.T., a flying E. brizo brizo male that I was pursuing abruptly flew to a dead branch on the prostrate skeleton of a shrub. The gray, barkless branch was about the diameter of a lead pencil, about half a meter above the ground, and parallel to it. The skipper lit on the ventral side of this branch and instantly embraced it by aligning its body with the branch and

\footnotetext{
*Published with the aid of a grant from the Museum of Comparative Zoology at Harvard College.

Manuscript received by the editor September 9, 1969
} 
folding its wings rooflike over its abdomen in the manner of many moths. The primaries fully covered the secondaries, and the apices of the primaries extended to the dorsolateral surfaces of the branch. In $E$. brizo the upper sides of the brown primaries are partly overscaled with gray - especially distad. As a result, the skipper blended with the branch and literally looked like "a bump on a log."

The speed with which the skipper took up its sleeping position is reminiscent of a rapidly flying female of Hesperia uncas macswaini MacNeill seen at 3170 meters in the White Mountains, Mono County, California, by MacNeill (1964: 38): "With no apparent hesitation it turned and disappeared into the eastern side of a dense Artemisia bush. Immediate investigation revealed the insect sitting with closed wings four inches within the tangle of terminal twigs and leaves. At first gentle, then vigorous disturbance of that portion of the shrub evoked no visible response upon the part of the insect. The specimen was captured by vigorously tapping the main branch, causing it to fall into an open container." Unlike this Hesperia female, however, the $E$. b. brizo male did not become torpid at once (the late afternoon was warm and rather sunny, with thin high cloud); it energetically flew off when I tried to bottle it a minute or so after it had lit. I followed for several minutes and about two hundred meters before losing it. In this interval the skipper seemed at times to investigate briefly other low dead branches.

In juniper and scrub oak habitat on the north rim of Palo Duro Canyon, 24 kilometers south of Claude, Armstrong County, Texas, on 12 April I968, at 1625 hours C.S.T., a flying female of $E$. brizo burgessi (Skinner) that I was pursuing suddenly settled on a gray branch of a small Quercus mohriana shrub that was barely beginning to leaf out. The branch was about a third of a meter above the ground and nearly parallel to it. The skipper lit on the dorsal side of the branch and at once assumed a mothlike posture as described above, except that the primaries scarcely embraced the branch. The afternoon was warm but cloudy at this time; and though the sun shone brightly again later and though some individuals in the population kept active, this female remained quiet. When she was photographed after almost an hour, her only move had been a ninetydegree rotation from the top to the side of the branch (fig. I). She was torpid and was bottled as soon as photographs were taken.

These two strikingly similar observations - made one year and 665 kilometers apart on both sexes and two of the three major differentiates of polytypic species $E$. brizo (treated in detail by Burns 

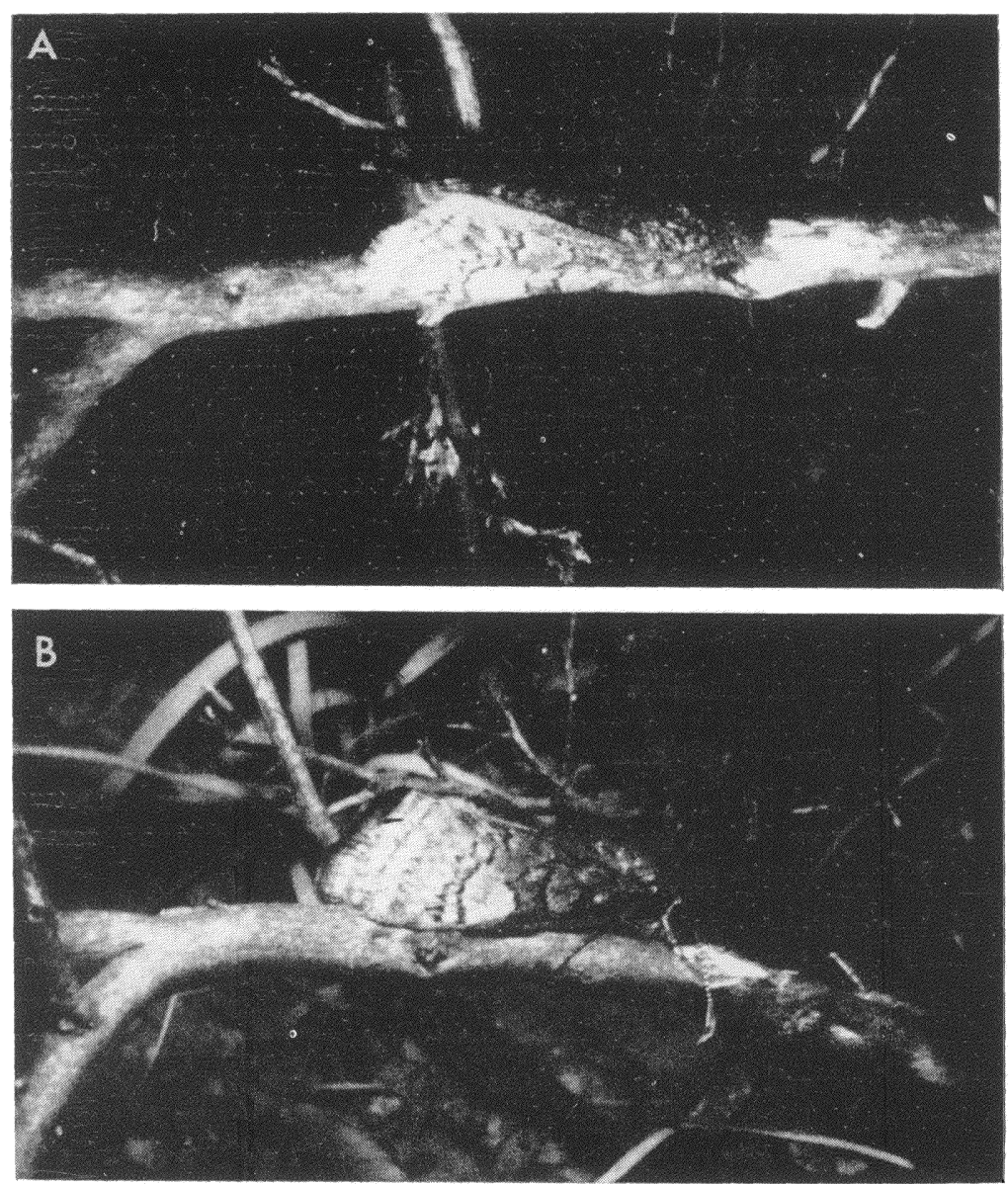

Fig. 1. Female of Erynnis brizo burgessi asleep on a branch of Quercus mohriana in Palo Duro Canyon, Texas, at 1720 hours C.S.T. on 12 April 1968. Her head is on the right. For further orientation compare fig. 2.

A. Dorsal view of female.

B. Right lateral view of female.

I964: 43-66, r95-205) - are enough to suggest strongly that this behavior is general for the entire transcontinental assemblage of populations. Wherever they occur in North America, these gray/ brown skippers are primarily in scrub oak habitat and so never lack a sleeping substrate of small, low, woody (often gray) branches. 


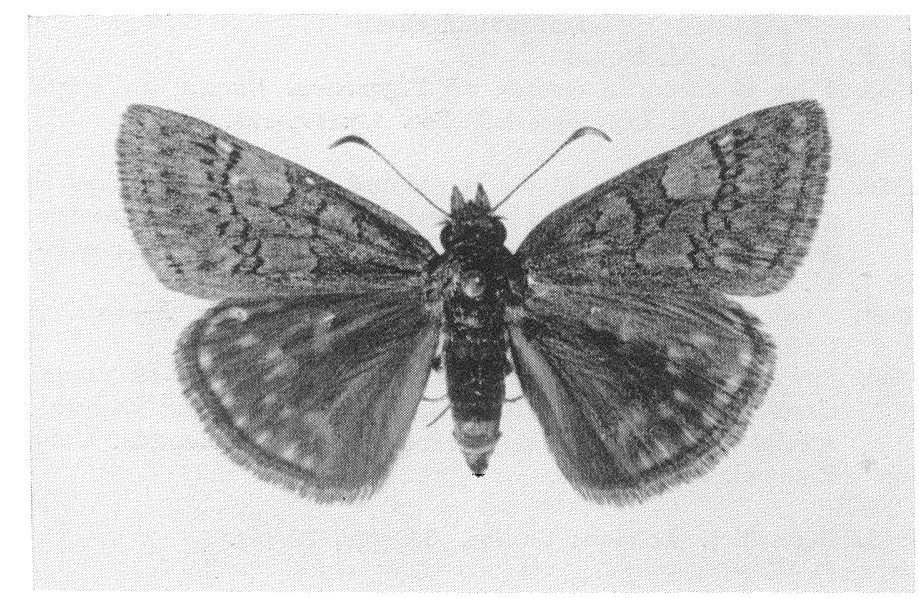

Fig. 2. The sleeping female of fig. 1 pinned and spread at a later time. Dorsal view. Her wingspread is about $38 \mathrm{~mm}$.

The sleeping position of E. brizo, unlike that of various butterflies, affords little to no protection from weather; the skipper is exposed, but it is concealed visually from many potential predators. The cryptic posture is assumed so abruptly that a fast-moving skipper almost vanishes into a more or less static landscape.

A different but related cryptic orientation has been observed in England in E. tages (Linnaeus), a species that was grouped with E. brizo in subgenus Erynnis by Burns (1964: 22-28). Sleeping individuals of $E$. tages characteristically rest appressed to flowerheads of forbs, grasses, and rushes. As in E. brizo, the wings are roofed noctuid-style over the abdomen and distally tend to be wrapped around the sleeping substrate. The flower-heads chosen are generally dead and brown and hence closely similar in color to the skippers themselves (Trimen 1857; Frohawk I884, I899, [1924]: I59-16I ; Tutt 1905-I906: 288-289; Ford 1945: pl. XIV, fig. 4).

\section{Acknowledgements}

I thank Douglas A. Graham for his prescience in bringing a flashequipped Brownie camera to Texas and for using it to take the photographs that appear in fig. I. Barry I. Kiefer kindly printed these photographs and Spencer J. Berry mounted them. This research was supported by National Science Foundation grant GB 5935 . 
Apter, R. L. ANd J. M. Burns

\section{Literature Cited}

1965. First Connecticut records of Thymelicus lineola, an introduced hesperiid. J. Lepidopterists' Soc. 19: 195-196.

Arthur, A. P.

1966. The present status of the introduced skipper, Thymelicus lineola (Ochs.) (Lepidoptera: Hesperiidae), in North America and

Burns, J. M. possible methods of control. Canadian Entomol. 98: 622-626.

1964. Evolution in skipper butterflies of the genus Erynnis. Univ. California Publ. Entomol. 37: 216 pp., 1 pl.

1966. Expanding distribution and evolutionary potential of Thymelicus lineola (Lepidoptera: Hesperiidae), an introduced skipper, with special reference to its appearance in British Columbia. Canadian Entomol. 98 : 859-866.

FORD, E. B.

1945. Butterflies. London: Collins. 368 pp., 72 pls.

FroHAWK, F. W.

1884. Sleeping position of Thanaos tages. Entomologist 17: 49.

1899. Resting position of Hesperia tages. Entomologist 32: 186-187.

[1924]. Natural history of British butterflies. Vol. 2. London: Hutchinson and Co. 206 pp., 29 pls.

HENSEL, H.

1966. A colonv of the European skipper Thymelicus lineola (Hesperiidae) at Edmundston, New Brunswick. J. Lepidopterists' Soc. 20: 28 .

MacNeill, C. D.

1964. The skippers of the genus Hesperia in western North America with special reference to California (Lepidoptera: Hesperiidae).

Trimen, R. Univ. California Publ. Entomol. 35: 230 pp., 8 pls.

1857. Position of the skippers in repose. Entomologist's Weekly Intelligencer. 2: 101 .

Tutr, J. W.

1905-1906. A natural history of the British butterflies. Vol. 1. London: Elliot Stock. 479 pp., 20 pls. 

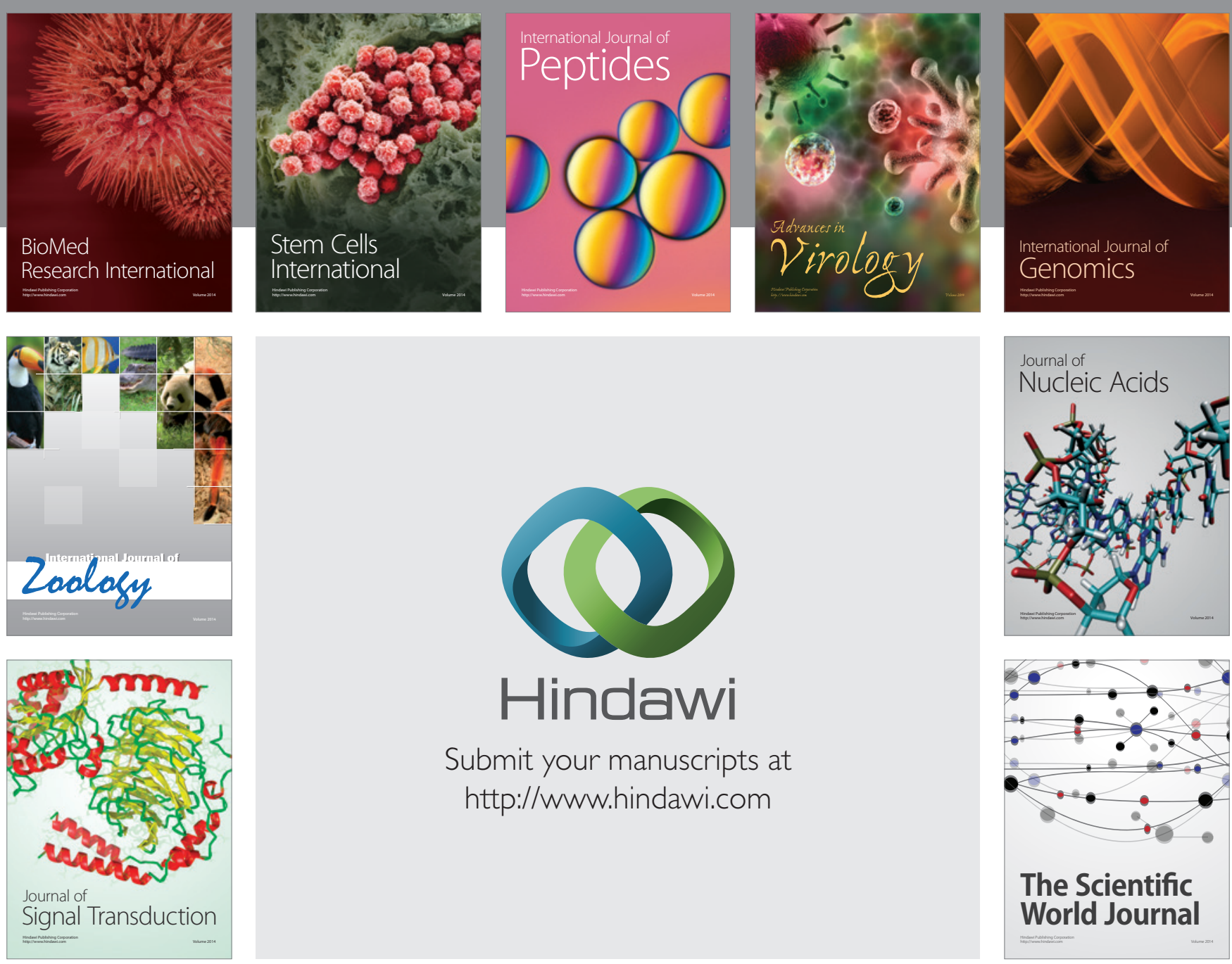

Submit your manuscripts at

http://www.hindawi.com
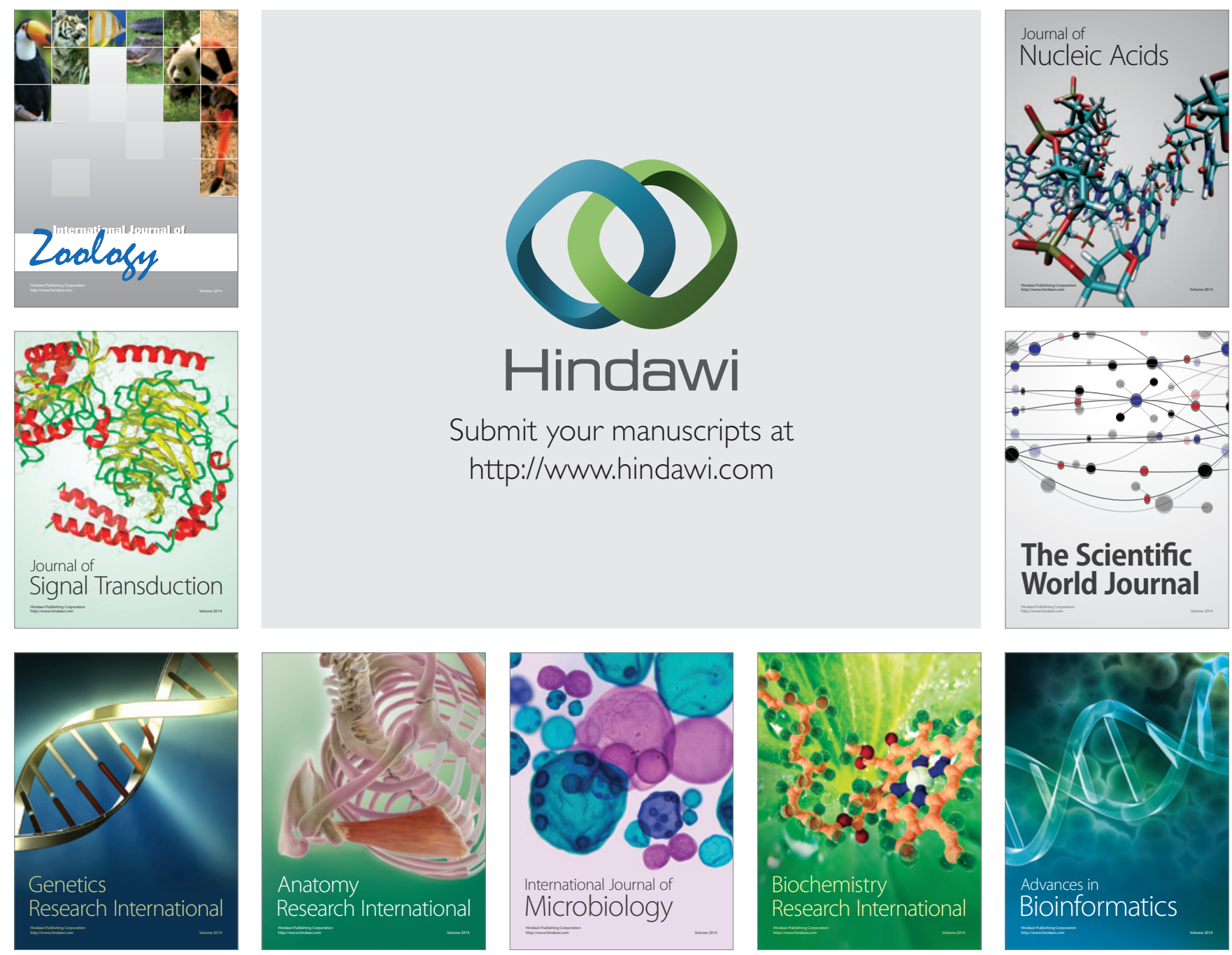

The Scientific World Journal
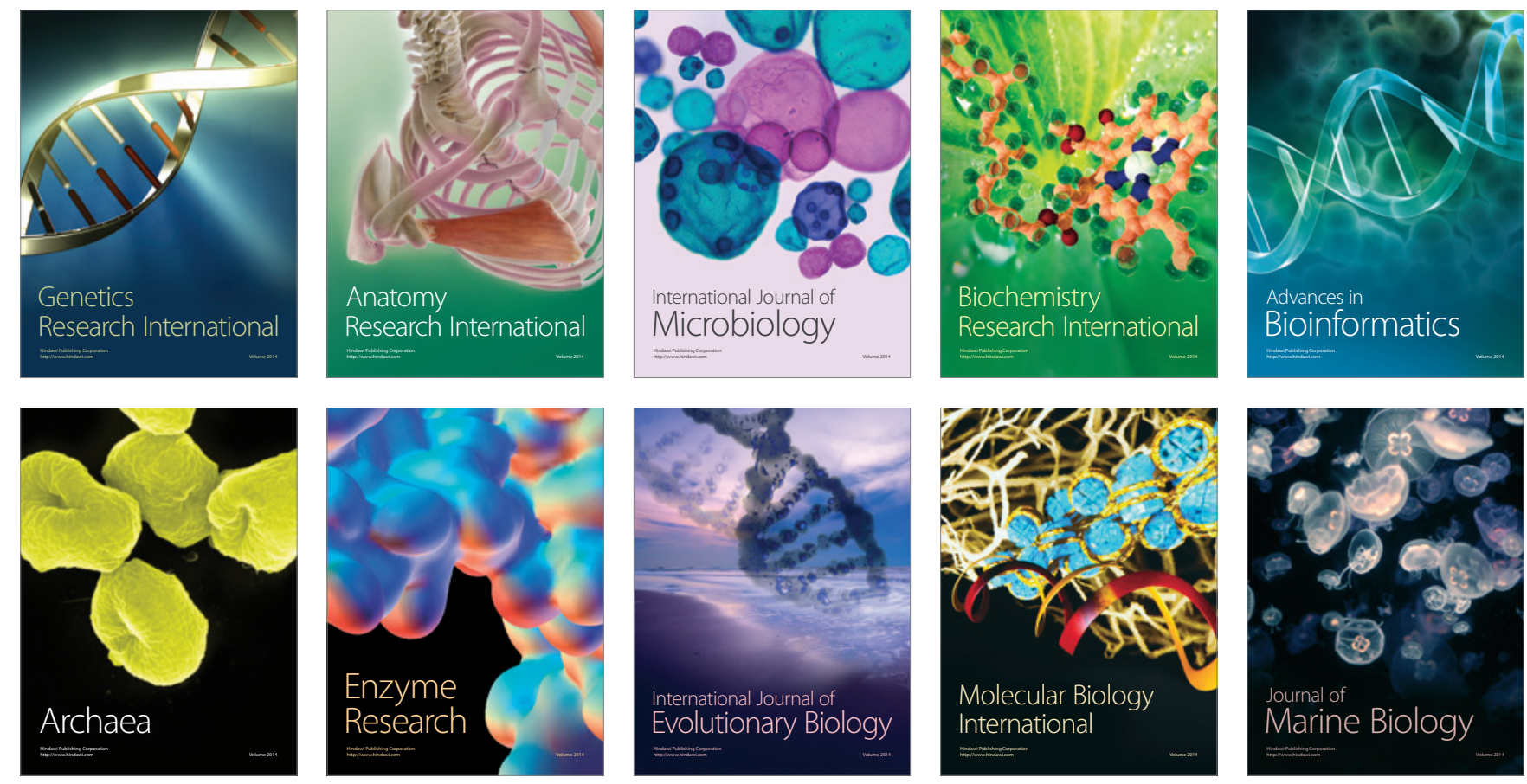